\title{
Case Study of a Functionally Graded Aluminum Part
}

\author{
Elisa Fracchia ${ }^{1}$ (D), Silvia Lombardo ${ }^{2}$ and Mario Rosso ${ }^{3, *}$ \\ 1 Department of Applied Science and Technology (DISAT), Politecnico di Torino, Viale T. Michel 5, \\ 15121 Alessandria, Italy; elisa.fracchia@polito.it \\ 2 Fonderie Officine Meccaniche Tonno (F.O.M.T) S.p.A., Viale Lidice, 8, Grugliasco, 10095 Torino, Italy; \\ silvia.lombardo@fomt.it \\ 3 Department of Applied Science and Technology (DISAT), Politecnico di Torino, \\ C.so Duca degli Abruzzi 24, 10129 Torino, Italy \\ * Correspondence: mario.rosso@polito.it; Tel.: +39-011-0904-604
}

Received: 31 May 2018; Accepted: 5 July 2018; Published: 10 July 2018

\begin{abstract}
The growing interest in aluminum alloys is due to the excellent ductility and mechanical strength, especially in relation with their lightness. These properties make aluminum alloys one of the most used and competitive materials in the automotive sectors. In fact, at the present day, automotive components must guarantee high mechanical and thermal properties in order to ensure low emissions of the vehicle. Despite that, harsh operating conditions can lead to a rupture in aluminum components, especially if subjected to both thermal and mechanical loads. In this panorama, aluminum functionally graded materials (FGMs) could be introduced, in order to produce a single piece with different properties that fulfill all the piece requirements. In this work, considering the typical application of the aluminum alloys as engine pistons, FGMs are realized by sequential gravity casting with the piston alloy EN AB 48000 and the alloy EN AB 42100. Tensile tests on these bi-metal parts give good results in terms of mechanical strength, elongation rates and alloys bonding.
\end{abstract}

Keywords: aluminum FGM; gravity casting; sequential casting; mechanical properties

\section{Introduction}

Functionally graded materials (FGMs) are advanced engineering composite materials that exhibit a spatial gradient in composition and/or morphology with the aim to satisfy specific requirements. There are three different types of FGMs [1]: chemical composition gradient FGMs, microstructural gradient FGMs and porosity gradient FGMs. In the chemical composition gradient FGMs, the chemical composition is gradually varied along the spatial position into the material. The microstructure gradient FGMs are characterized by a microstructural variation into the same material: the microstructure is tailored with the aim to obtain the required properties in certain parts of the piece. Finally, in the porosity gradient FGMs, the porosity changes with the space position into the material, changing pore shape and/or their size. These materials found applications in a variety of field, such as aerospace, nuclear, electrical, biomedical, defense and automotive sectors [1-3].

There are several methods to obtain FGMs: gas-based methods, liquid-phase methods and solid-phase methods [2], and among all this production processes, metallic FGMs are commonly obtained with centrifugal casting, squeeze casting, gravity casting, investment casting, sintering and infiltration techniques [4,5]. Within the casting process panorama, gravity casting is one of the simplest methods to produce FGMs. This process employs a permanent mould, commonly realized in steel. The mould is opportunely coated with a protective paint and then pre-heated at a certain temperature that must be constant in order to facilitate the cast-removal. The cast production sequence involves different steps: (i) mould cleaning; (ii) casting process; (iii) cast extraction; and (iv) sprue cut. 
This casting process causes a certain grade of defects, intrinsically generated by the process [6], and the final properties of castings are related to defects as well as to die design and microstructures.

Parameters that could affect the casting process causing defects are: (i) temperatures (pouring, pre-heat); (ii) time (pouring, melt holding, degasification); (iii) material and thickness of the mould-coating; (iv) mould design; and (v) pouring velocity. The types of defects and their ranking in gravity casting were classified in [7] as: (i) gas/air porosity, about $45 \%$; (ii) shrinkage, $44 \%$; (iii) filling related problems, 38\%; (iv) cracks, 33\%; (v) inclusions, 28\%; and (vi) metal/die interactions, $23 \%$.

Focusing on the combination FGM-automotive applications, and considering the high presence of the aluminum alloys in this sector [8], it is certainly possible to combine the aluminum alloys with the concept of FGM [9-12]. In fact, aluminum alloys are considered as very interesting materials, because of their lightweight, especially if compared with ferrous alloys, which lead to an important decrease in fuel consumption reducing the polluting emissions, and their high specific resistance and ductility [13,14]. Particularly, FGMs in the automotive industries could be used for engine pistons [9], leaf springs [15] and many other applications. Focusing on the piston production techniques, the most employed processes are casting and forging [16-21]. In [22], Park et al. optimized the forging process to produce aluminum pistons employing aluminum powder; in the research [23], high performance pistons were produced by additive manufacturing; and in [24], the forging process was performed on the piston-wrought-alloy EN AW 4032 (AlSi12,5MgCuNi). In [9], a microstructure-gradient FGM aluminum piston was produced by centrifugal casting: the hypereutectic alloy A390 was melted and poured into a spinning mould, and the design of the die leads to obtain a strong segregation of the primary silicon particles on the head portion of the piston that leads to an increase in wear and hardness. Similarly, with the same producing process, Huang et al. [25] realized a chemical-composition-gradient FGMs with AlSi18CuMgNi alloy.

Engine pistons are commonly produced employing aluminum-silicon alloys because of their high mechanical resistance at high temperature and good fatigue behavior [16,25-32]. Particularly, the most widely used piston alloy is the EN AC 48000. However, this alloy exhibits poor ductility and low elongation at rupture that could lead to fatigue failure in the piston skirt. This can be avoided by realizing a FGM employing a more ductile alloy in the skirt and a mechanical and thermal resistant alloy in the piston crown. In this paper, a chemical-composition-gradient FGM for automotive piston was prepared by sequential gravity casting using the piston alloy (EN AC 48000) in contact with a more ductile composition (EN AC 42100). This FGM was made focusing on the process variables and their influence on the mechanical properties obtained.

\section{Materials and Methods}

\subsection{Materials}

FGM was realized by gravity casting using two different aluminum alloys: EN AC 48000 (AlSi12CuNiMg) and EN AC 42100 (AlSi7Mg0.3) with the compositions reported in Table 1.

Table 1. Alloy composition [33].

\begin{tabular}{ccccccccccc}
\hline \multicolumn{10}{c}{ EN AC 48000 (AlSi12CuNiMg) } \\
\hline Elements & $\mathrm{Si}$ & $\mathrm{Fe}$ & $\mathrm{Cu}$ & $\mathrm{Mn}$ & $\mathrm{Mg}$ & $\mathrm{Ni}$ & $\mathrm{Zn}$ & $\mathrm{Ti}$ & $\mathrm{Al}$ \\
Min (\%) & 10.5 & - & 0.8 & - & 0.8 & 0.7 & - & - & Res. \\
Max (\%) & 13.5 & 0.7 & 1.5 & 0.35 & 1.5 & 1.3 & 0.35 & 0.25 & \\
\hline \multicolumn{10}{c}{ EN AC 42100 (AlSi7Mg0.3) } \\
\hline Elements & $\mathrm{Si}$ & $\mathrm{Fe}$ & $\mathrm{Cu}$ & $\mathrm{Mn}$ & $\mathrm{Mg}$ & $\mathrm{Zn}$ & $\mathrm{Ti}$ & $\mathrm{Al}$ \\
Min (\%) & 6.5 & - & - & - & 0.25 & - & - & Res. \\
Max (\%) & 7.5 & 0.19 & 0.05 & 0.10 & 0.45 & 0.07 & 0.25 & \\
\hline
\end{tabular}


The AlSi12CuNiMg alloy, also known as a piston alloy, is commonly used to produce piston in the automotive sector. It has eutectic composition and the maximum elongation at rupture of about $1 \%$. On the other hand, the AlSi7Mg0.3 alloy is a hypoeutectic aluminu-silicon alloy that contains a small amount of $\mathrm{Mg}$ and could reach $8 \%$ of elongation at rupture. $\mathrm{Cu}$ and $\mathrm{Mg}$ are added to increase the mechanical properties as a result of the precipitation strengthening after heat treatment, while $\mathrm{Ni}$, added in the piston alloy, increases the high temperature resistance [34].

\subsection{Methods}

An aluminum FGM was obtained with the sequential gravity casting of the composition A (AlSi7Mg0.3) followed by the composition B (AlSi12CuNiMg). Overall, five types of manual castings were performed using a mould (made in heat treated steel) that permitted to obtain square bars of $25 \mathrm{~mm} \times 125 \mathrm{~mm} \times 15 \mathrm{~mm}$. Optimization of the casting process included: (i) selection of the pouring order for the two compositions; (ii) casting temperatures of the alloys; (iii) waiting time between the sequential castings; and (iv) mould temperature.

The pouring order depends on the alloy-gap between solidus and liquidus temperatures. As previously demonstrated by DSC analysis (Differential Scanning Calorimetry) and detailed in $[10,11]$, the hypoeutectic alloy (AlSi7Mg0.3) was the first poured composition for its larger gap of solidification (Figure 1).
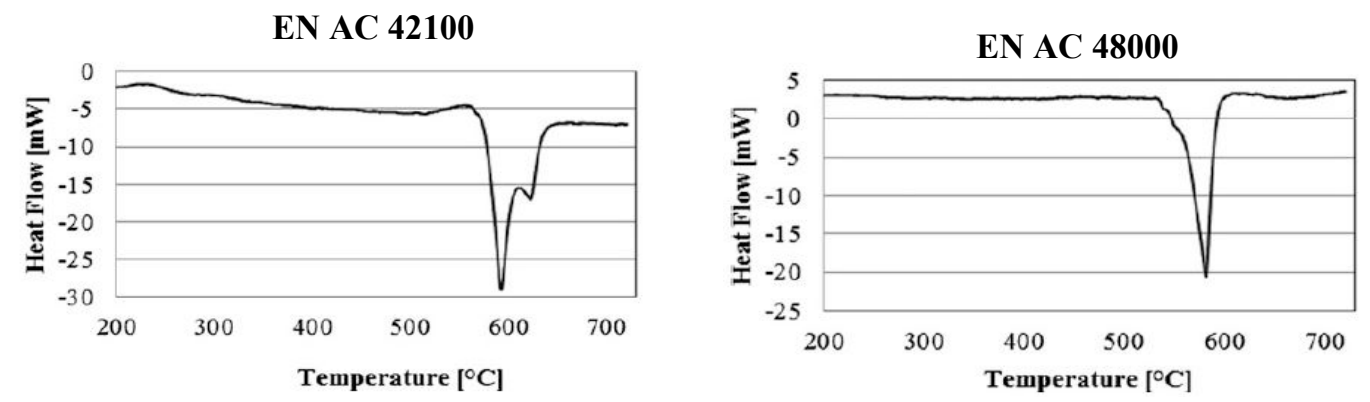

Figure 1. Differential Scanning Calorimetry (DSC) analysis [10].

The DSC curve of the hypoeutectic alloy presents two peaks: the eutectic temperature and the liquidus temperature (as can be seen in Figure 1). This gap of solidification permits to obtain a barrier effect for the second alloy (with eutectic composition) when poured, due to the solidification of the alpha-phase of the first alloy that avoids the mixing of the composition. At the same time, it is important to perform the second casting during the solidification temperature gap of the first alloy, in order to allow a metallurgical bond due to the mixing of the Si-rich phase of the second poured alloy inside the interdendritic channels of the first one.

Casting temperatures of the alloys must ensure the bonding of the two compositions avoiding the premature solidification of the first alloy poured. The waiting time between the sequential castings depends on both the temperature gap liquidus-solidus for the two alloys and the casting temperature of the alloys; in fact, this time must permit the bond of the alloys at the interfaces avoiding the mixing of the compositions. The mould temperature influences the degassing process: the higher the temperature of the mould, the faster the elimination of the humidity is.

For all these reasons, alloy temperatures were set at $710^{\circ} \mathrm{C}(\mathrm{AlSi7Mg} 0.3)$ and $750{ }^{\circ} \mathrm{C}$ (AlSi12CuNiMg), with a mould temperature of $400^{\circ} \mathrm{C}$ and several waiting time in the range of $10-50 \mathrm{~s}$, to investigate their effect on the bonding region. No modification or refining was performed during the melting.

After the casting process, qualitatively RX analysis (X-ray radioscopic inspection) was carried out to evaluate the bonding rate, the porosity and the inclusion grade into the casted parts, especially at the interfaces between the two compositions. These observations were conducted by a Bosello High Technology Industrial X-Ray system on the casted parts. 
Tensile tests were done by a ZWICK ROELL machine with the aim to evaluate the resistance of the joint between the alloys for different elapsing time. Each casting specimen was machined into the typical dog-bone shape. Considering the composite nature of the FGMs and the possibility to obtain two specimens for each FGM casted, which lead to perform a better statistical analysis of the results, it was decided to realize rectangular-shape specimens, following the standard ASTM B557-15 for samples preparation and the ASTM E8 for testing methods. After tensile tests, the fracture surfaces were observed with the scanning electron microscope (SEM), Leo 1450VP.

\section{Results and Discussion}

\subsection{RX Analysis}

$R X$ images of the most representative samples were shown in Figure 2. In the middle of the specimens, inclusions and gas porosities that appear white were observed, as well as reported in [35], particularly in the EN AC 48000.

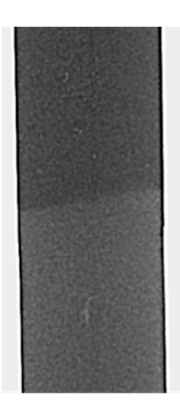

$\# 1$

Elapsing
time 10 seconds

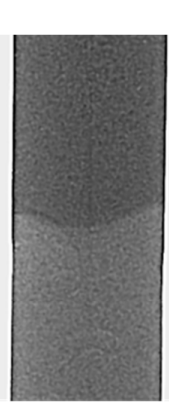

$\# 2$

Elapsing

time 20

seconds

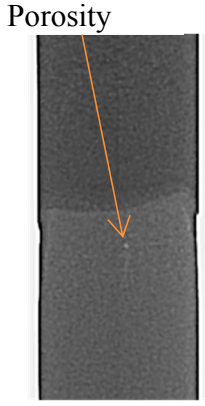

\#3

Elapsing

time 30

seconds


\#5

time 50

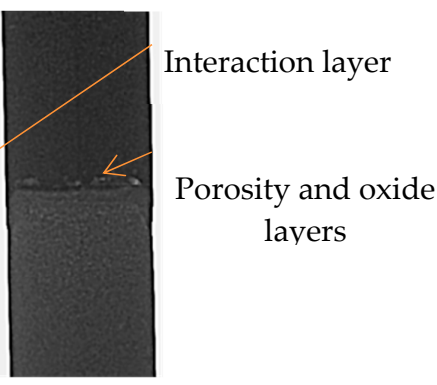

seconds

Figure 2. Sample interfaces EN AC 48000 /EN AC 42100 obtained with RX analysis after sequential gravity casting at different conditions of waiting time. AlSi12CuNiMg is the dark grey part (the lower part for each image) while the other one is AlSi7Mg0.3.

After the waiting time of ten seconds, the interface appeared sharp. After twenty seconds, the solidification of the first alloy was interrupted by the casting of the second one that led to the formation of an interaction layer with the re-melting of the interface of the first poured alloy. Over thirty seconds, the interface area appeared sharp with a high grade of porosity and oxide films [36,37]. The interaction region where the two alloys met became inhomogeneous for excessive waiting time, as shown in part \#5 of Figure 2.

\subsection{Tensile Tests}

Samples were mechanically tested for tensile resistance and results were reported in Figure 3 and in Table 2. At least three samples per each condition have been investigated. Samples with elapsing time of $40 \mathrm{~s}$ were not tested, while results for samples with an elapsing time of $50 \mathrm{~s}$ were shown in Figure 3, only to demonstrate the blatant reduction in mechanical properties.

As visible in yield strength, elongation at break and load at break increased with the increase in elapsing time until $30 \mathrm{~s}$. Moreover, standard deviation decreased between elapsing time 20 and $30 \mathrm{~s}$ for each parameter. The tests presenting higher standard deviation had a high variability in fracture behavior of the specimens: in fact, for each elapsing time, some samples broke in correspondence of porosity and shrinkage (as shown in Figure 4A obtained with the SEM), while others broke because of oxide films (as shown in Figure 4B obtained with and Energy Dispersive X-Ray Spectroscopy EDS), causing fluctuations in both values of mechanical resistance and elongation. 


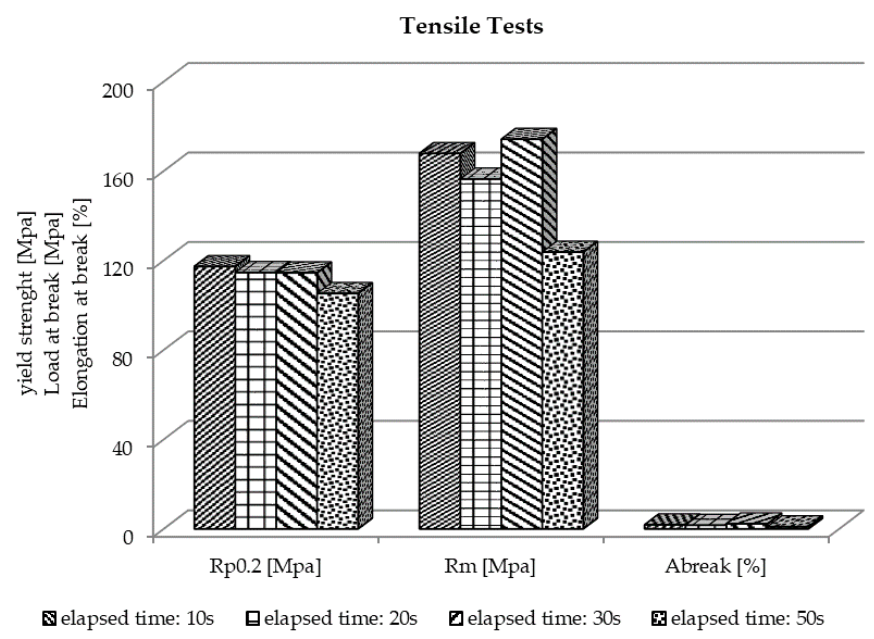

Figure 3. Mechanical properties obtained after tensile tests.

Table 2. Mechanical properties obtained with tensile tests. (E.t. = elapsing time).

\begin{tabular}{ccccc}
\hline \multicolumn{2}{c}{ Mechanical Properties } & $\mathbf{R}_{\mathbf{p 0 . 2}}$ (Mpa) & $\mathbf{R}_{\mathbf{m}(\mathbf{M p a})}$ & $\mathbf{A}_{\text {break }}(\mathbf{\%})$ \\
\hline \multirow{2}{*}{ E.t. $10 \mathrm{~s}$} & Average & 117.36 & 167.89 & 1.87 \\
& Standard deviation & 4.32 & 9.61 & 0.65 \\
\hline \multirow{2}{*}{ E.t. $20 \mathrm{~s}$} & Average & 114.65 & 156.45 & 1.65 \\
& Standard deviation & 3.23 & 19.23 & 0.95 \\
\hline \multirow{2}{*}{ E.t. $30 \mathrm{~s}$} & Average & 114.53 & 174.25 & 2.28 \\
& Standard deviation & 4.50 & 15.46 & 0.26 \\
\hline \multirow{2}{*}{ E.t. $50 \mathrm{~s}$} & Average & 105.28 & 123.77 & 0.97 \\
& Standard deviation & 1.87 & 0.41 & 0.08 \\
\hline
\end{tabular}


Figure 4. (A) Sample with fracture in correspondence of gas porosity and shrinkage porosity (SEM analysis).

(B) Sample with presence of an oxide film (Energy Dispersive X-Ray Spectroscopy EDS analysis).

Based on the obtained evaluation of the results and considering the high standard deviations, elapsing time of $30 \mathrm{~s}$ seemed to give the best results in terms of elongation at rupture $(2.28 \%)$, while the yield strength was similar to that with the timespan 10-20 s (about 114-117 MPa). In all the cases, $50 \mathrm{~s}$ of elapsing time gave the worst results, demonstrating that the discontinuity caused by porosity and oxide layers seen before in the RX analysis (Figure 2) weakened the interface region between the two alloys. 


\subsection{Fracture Surfaces}

Analysis of the fracture post-tensile tests showed various defects, especially for higher elapsing time. Shrinkage porosities, gas porosity and oxide layers were detected in more details in Table 3, which was also because of the surface turbulence associated with the filling of the mould as well as in [38].

Table 3. Surface fractures for each elapsing time.

\begin{tabular}{l|lll}
\hline \multicolumn{1}{c|}{ Elapsing Time E.t. } & Fracture Surfaces & Fracture Details \\
\hline $\begin{array}{l}\text { E.t.10s: fragile fractures } \\
\text { in the AlSi7Mg0.3 caused } \\
\text { by shrinkage porosity. }\end{array}$ & & &
\end{tabular}

E.t.20s: fragile fractures in the AlSi7Mg0.3 caused by oxide and porosity.
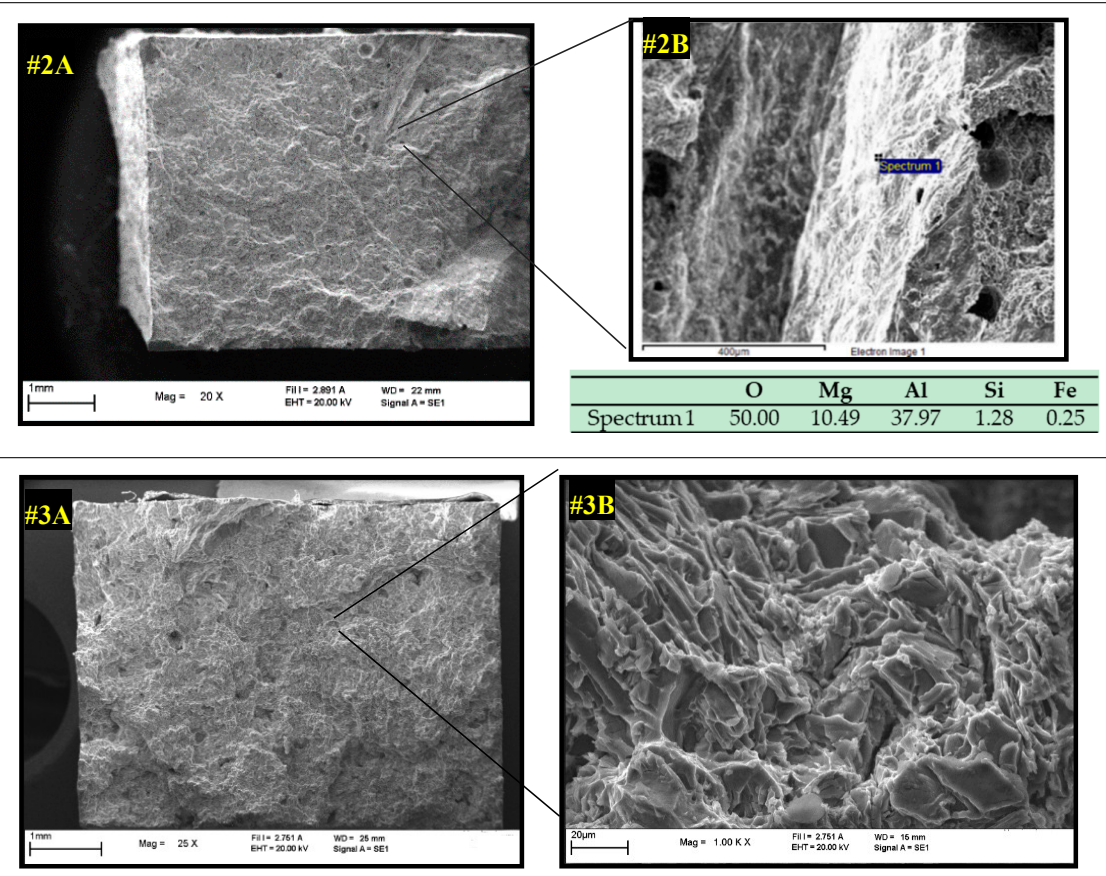

E.t.30s: fracture in the AlSi7Mg0.3 caused by small quantity of gas porosity.
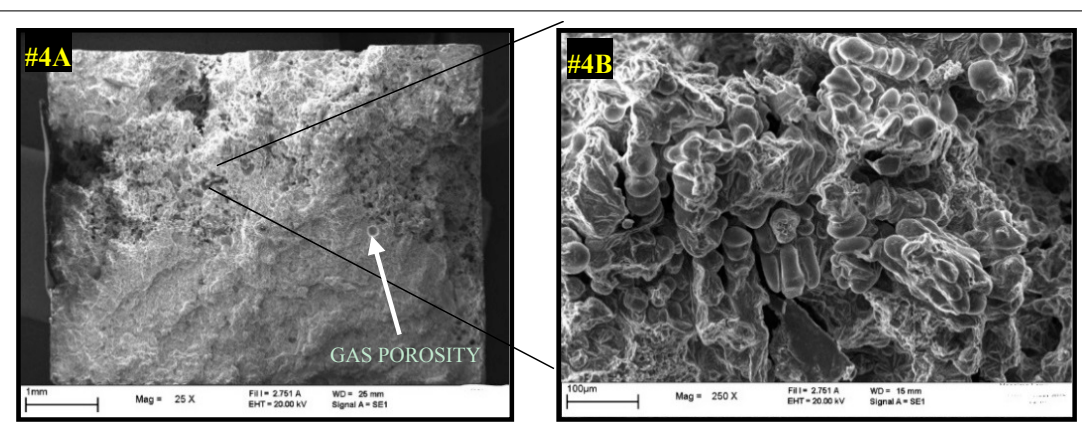

E.t.50s: fragile fractures at the interface area caused by oxide, shrinkage and gas porosity.

As expected [10], most of the fractures happened in the weakest alloy (A1Si7Mg0.3). In just one case (E.t. $50 \mathrm{~s}$ ), the sample reached rupture exactly into the bonding layer because of high presence of slag that weakened the meeting area. 
Table 3 shows details about microstructures and EDX analysis for four surface fractures:

(\#1) The sample with E.t. 10s broke in the weakest alloy, presenting shrinkage porosity in different areas of the surface (Table $3 \# 1 B$ ).

(\#2) The sample with E.t. 20 s broke in the weakest alloy but close to the interface (in the presence of $\mathrm{Cu}$ and $\mathrm{Ni}$ in the EDS analysis). As shown in Table 3\#2B, an oxide layer was detected.

(\#3) The sample with E.t. $30 \mathrm{~s}$ broke in the weakest alloy and presents the highest elongation. The surface is free from macro defects, as shown in Table 3 \#3B.

(\#4) Surface fracture of the sample with E.t. $50 \mathrm{~s}$ was characterized by shrinkage porosity, with typical dendrite structures, gas porosity and oxide layers (Table $3 \# 4 \mathrm{~A}, \# 4 \mathrm{~B}$ ).

\section{Conclusions}

Sequential gravity castings of FGMs in aluminum alloys were performed. The elapsing time between the casting of the two alloys was chosen as a priority parameter in order to optimize the process obtaining effective bonding between the two compositions.

After various casting processes at different elapsing time up to $50 \mathrm{~s}$, tensile tests were made to characterize the bonding behavior in each casting. Tests showed an increase in the mechanical strength after $20 \mathrm{~s}$ and then a decrease before $30 \mathrm{~s}$. For shorter time, the alloys were mixed together in a larger and not defined area: the FGM goal was lost and the final mechanical properties were weaker. In order to maintain the alloys and their peculiar properties divided, the optimized time was between 20 and $30 \mathrm{s.}$

Certainly, the mechanical properties obtained were in line with results of previous work [10], with an increase in the mechanical resistance and the yield strength. Most of the fractures occurred in the AlSi7Mg0.3 region, which has lower mechanical resistance than AlSi12CuNiMg. The presence of the hypoeutectic alloy permitted to reach an elongation of $2 \%$.

Overall, it appeared that only the presence of oxide and slag has caused fracture at the interface of the alloys. High elapsing time emphasizes this trend: long E.t. does not allow an effective remelting of the AlSi7Mg0.3 surface and the oxide scale, if present, remains confined into the interface area, transforming it into a weak point.

These results could be further enhanced by improving the cleanliness of the bath to remove some oxide concerns and applying a heat treatment.

Author Contributions: Conceptualization, M.R. and S.L.; methodology, S.L. and E.F.; RX analysis, S.L.; investigation and tensile tests, E.F.; data curation, E.F.; writing of the original draft preparation, E.F.; supervision, M.R.; project administration, M.R.

Funding: This research received no external funding.

Conflicts of Interest: The authors declare no conflicts of interest.

\section{References}

1. Mahamood, R.M.; Akinlabi, E.T. Types of Functionally Graded Materials and Their Areas of Application. In Mining, Metallurgy and Materials Engineering; Springer: Cham, Switzerland, 2017.

2. Naebe, M.; Shirvanimoghaddam, K. Functionally graded materials: A review of fabrication and properties. Appl. Mater. Today 2016, 5, 223-245. [CrossRef]

3. Khan, S. Analysis of Tribological Applications of Functionally Graded Materials in Mobility Engineering. Int. J. Sci. Eng. Res. 2015, 6, 1150-1160.

4. Sobczak, J.J.; Drenchev, L. Metallic Functionally Graded Materials: A Specific Class of Advanced Composites. J. Mater. Sci. Technol. 2013, 29, 297-316. [CrossRef]

5. Singh, S.; Singh, R. Development of functionally graded material by fused deposition modelling assisted investment casting. J. Manuf. Process. 2016, 24, 38-45. [CrossRef]

6. Malhotra, V.; Kumar, Y. Study of Process Parameters of Gravity Die Casting Defects. Int. J. Mech. Eng. Technol. 2016, 7, 208-211. 
7. Bonollo, F.; Fiorese, E.; Timelli, G.; Arnberg, L.; Adamane, A.C.R. StaCast project: From a survey of European aluminium alloys foundries to new standards on defect classification and on mechanical potential of casting alloys. In Proceedings of the 71st World Foundry Congress: Advanced Sustainable Foundry, WFC 2014, Bilbao, Spain, 19-21 May 2014.

8. Fridlyander, I.N.; Sister, V.G.; Grushko, O.E.; Berstenev, V.V.; Sheveleva, L.M.; Ivanova, L.A. Aluminum alloys: Promising materials in the automotive industry. Met. Sci. Heat Treat. 2002, 44, 365-370. [CrossRef]

9. Arsha, A.G.; Jayakumar, E.; Rajan, T.P.D.; Antony, V.; Pai, B.C. Design and fabrication of functionally graded in-situ aluminium composites for automotive pistons. Mater. Des. 2015, 88, 1201-1209. [CrossRef]

10. Rosso, M.; Lombardo, S.; Gobber, F. Sequential gravity casting in functionally graded aluminum alloys development. In Light Metals; Springer: Cham, Switzerland, 2017.

11. Lombardo, S.; Peter, I.; Rosso, M. Gravity casting of variable composition Al alloys: Innovation and new potentialities. In Proceedings of the Aluminum Two Thousand World Congress and International Conference on Extrusion and Benchmark ICEB 2017, Verona, Italy, 20-24 June 2017.

12. Di Ciano, M.; Caron, E.J.F.R.; Weckman, D.C.; Wells, M.A. Interface Formation During Fusion ${ }^{\mathrm{TM}}$ Casting of AA3003/AA4045 Aluminum Alloy Ingots. Metall. Mater. Trans. B Process Metall. Mater. Process. Sci. 2015, 46, 2674-2691. [CrossRef]

13. Cui, J.; Roven, H.J. Recycling of automotive aluminum. Trans. Nonferr. Met. Soc. China 2010, 20, $2057-2063$. [CrossRef]

14. Płonka, B.; Kłyszewski, A.; Senderski, J.; Lech-Grega, M. Application of Al alloys, in the form of cast billet, as stock material for the die forging in automotive industry. Arch. Civ. Mech. Eng. 2008, 8, 149-156. [CrossRef]

15. Mehta, D.U.; Roy, D.K.; Saha, K.N. Nonlinear Analysis of Leaf Springs of Functionally Graded Materials. Procedia Eng. 2013, 51, 538-543.

16. European Aluminium Association. The Aluminium Automotive Manual; European Aluminium Association: Bruxelles, Belgium, 2013; pp. 1-17.

17. Bonollo, F.; Urban, J.; Bonatto, B.; Botter, M. Gravity and low pressure die casting of aluminium alloys: A technical and economical benchmark. Metall. Ital. 2005, 5, 23-32.

18. Kuhlman, G.W. Forging of aluminum alloys. In ASM Handbook, Volume 14A: Metalworking: Bulk Forming; Semiatin, S.L., Ed.; ASM: Almere, The Netherlands, 2005; pp. 299-312.

19. Umezawa, O.; Takagi, H.; Sekiguchi, T.; Yamashita, T.; Miyamoto, N. Novel process development with continuous casting and precise forging for AL-SI alloys to produce an engine piston. Ceram. Trans. 2009, 207, 189-200.

20. Choi, J.I.; Park, J.H.; Kim, J.H.; Kim, S.K.; Kim, Y.H.; Lee, J.H. A study on manufacturing of aluminum automotive piston by thixoforging. Int. J. Adv. Manuf. Technol. 2007, 32, 280-287. [CrossRef]

21. Hosokawa, H.; Higashi, K. Materials design for industrial forming process in high-strain-rate superplastic Al-Si alloy. Mater. Res. Innov. 2001, 4, 231-236. [CrossRef]

22. Park, J.O.; Kim, K.J.; Kang, D.Y.; Lee, Y.S.; Kim, Y.H. An experimental study on the optimization of powder forging process parameters for an aluminum-alloy piston. J. Mater. Process. Technol. 2001, 113, 486-492. [CrossRef]

23. Barbieri, S.G.; Giacopini, M.; Mangeruga, V.; Mantovani, S. A Design Strategy Based on Topology Optimization Techniques for an Additive Manufactured High Performance Engine Piston. Procedia Manuf. 2017, 11, 641-649. [CrossRef]

24. Balducci, E.; Ceschini, L.; Morri, A.; Morri, A. EN AW-4032 T6 Piston Alloy After High-Temperature Exposure: Residual Strength and Microstructural Features. J. Mater. Eng. Perform. 2017, 26, 3802-3812. [CrossRef]

25. Huang, X.; Liu, C.; Lv, X.; Liu, G.; Li, F. Aluminum alloy pistons reinforced with SiC fabricated by centrifugal casting. J. Mater. Process. Technol. 2011, 211, 1540-1546. [CrossRef]

26. Nicoletto, G.; Riva, E.; di Filippo, A. High temperature fatigue behavior of eutectic Al-Si-Alloys used for piston production. Procedia Eng. 2014, 74, 157-160. [CrossRef]

27. Dutta, S.; Kaiser, M.S. Recrystallization kinetics in Aluminum piston. Procedia Eng. 2014, 90, 188-192. [CrossRef]

28. Mbuya, T.O.; Sinclair, I.; Moffat, A.J.; Reed, P.A.S. Micromechanisms of fatigue crack growth in cast aluminium piston alloys. Int. J. Fatigue 2012, 42, 227-237. [CrossRef]

29. Zeren, M. The effect of heat-treatment on aluminum-based piston alloys. Mater. Des. 2007, 28, $2511-2517$. [CrossRef] 
30. Ma, C.; Cheng, D.; Zhu, X.; Yan, Z.; Fu, J.; Yu, J.; Liu, Z.; Yu, G.; Zheng, S. Investigation of a self-lubricating coating for diesel engine pistons, as produced by combined microarc oxidation and electrophoresis. Wear 2018, 394-395, 109-112. [CrossRef]

31. European Aluminmium Association. Aluminium in Cars; European Aluminmium Association: Bruxelles, Belgium, 2011; Volume 10.

32. Dyzia, M. Aluminum matrix composite (AlSi7Mg2Sr0.03/SiCp) pistons obtained by mechanical mixing method. Materials 2018, 11, 14 .

33. UNI Ente Nazionale Italiano di Unificazione. UNI EN 1706'; UNI Ente Nazionale Italiano di Unificazione: Geneva, Switzerland, 2010; p. 30.

34. Stadler, F.; Antrekowitsch, H.; Fragner, W.; Kaufmann, H.; Pinatel, E.R.; Uggowitzer, P.J. The effect of main alloying elements on the physical properties of Al-Si foundry alloys. Mater. Sci. Eng. A 2013, 560, 481-491. [CrossRef]

35. Pirovano, R.; Mascetti, S. Tracking of collapsed bubbles during a filling simulation Die-casting. Metall. Ital. 2016, 6, 37-40.

36. Dispinar, D.; Campbell, J. Porosity, hydrogen and bifilm content in Al alloy castings. Mater. Sci. Eng. A 2011, 528, 3860-3865. [CrossRef]

37. Dispinar, D.; Akhtar, S.; Nordmark, A.; di Sabatino, M.; Arnberg, L. Degassing, hydrogen and porosity phenomena in A356. Mater. Sci. Eng. A 2010, 527, 3719-3725. [CrossRef]

38. El-Sayed, M.A.; Hassanin, H.; Essa, K. Effect of casting practice on the reliability of Al cast alloys. Int. J. Cast Met. Res. 2016, 29, 350-354. [CrossRef]

(C) 2018 by the authors. Licensee MDPI, Basel, Switzerland. This article is an open access article distributed under the terms and conditions of the Creative Commons Attribution (CC BY) license (http:/ / creativecommons.org/licenses/by/4.0/). 